\title{
Can slide positivity rates predict malaria transmission?
}

\author{
Yan $\mathrm{Bi}^{1,2}$, Wenbiao Hu${ }^{3}$, Huaxin Liư ${ }^{4}$, Yujiang Xiao ${ }^{4}$, Yuming Guo ${ }^{1}$, Shimei Chen ${ }^{4}$, Laifa Zhao ${ }^{4}$ and Shilu Tong ${ }^{1 *}$
}

\begin{abstract}
Background: Malaria is a significant threat to population health in the border areas of Yunnan Province, China. How to accurately measure malaria transmission is an important issue. This study aimed to examine the role of slide positivity rates (SPR) in malaria transmission in Mengla County, Yunnan Province, China.

Methods: Data on annual malaria cases, SPR and socio-economic factors for the period of 1993 to 2008 were obtained from the Center for Disease Control and Prevention (CDC) and the Bureau of Statistics, Mengla, China. Multiple linear regression models were conducted to evaluate the relationship between socio-ecologic factors and malaria incidence.

Results: The results show that SPR was significantly positively associated with the malaria incidence rates. The SPR $(\beta=1.244, p=0.000$ ) alone and combination ( $S P R, \beta=1.326, p<0.001)$ with other predictors can explain about $85 \%$ and $95 \%$ of variation in malaria transmission, respectively. Every $1 \%$ increase in SPR corresponded to an increase of $1.76 / 100,000$ in malaria incidence rates.

Conclusion: SPR is a strong predictor of malaria transmission, and can be used to improve the planning and implementation of malaria elimination programmes in Mengla and other similar locations. SPR might also be a useful indicator of malaria early warning systems in China.
\end{abstract}

Keywords: Malaria transmission, Slide positivity rates, Malaria elimination, International border areas, China

\section{Background}

Malaria is one of the major public health problems in China, especially in Yunnan Province, which has significant mortality, morbidity and economic burden. Yunnan Province is a malarial hyper-endemic area and had the highest number of malaria cases and deaths for more than 10 years until 2005 in China [1,2]. The outbreaks of malaria happen annually along border areas in Yunnan, China. The likelihood of imported malaria cases has been increased along the border areas between Yunnan and Myanmar, Laos and Vietnam over recent years, due to increased trade and tourism in these areas [2,3]. In order to control malaria it is important to enhance disease surveillance and evaluation of malaria transmission $[4,5]$ in this endemic region.

The intensity of malaria transmission can be estimated using different indicators such as annual blood examination

\footnotetext{
* Correspondence: s.tong@qut.edu.au

${ }^{1}$ School of Public Health and Social Work, Institute of Health and Biomedical Innovation, Queensland University of Technology, Victoria Park Road, Kelvin Grove, 4059, Brisbane, Australia

Full list of author information is available at the end of the article
}

rate (ABER), annual parasite index (API), slide positivity rate (SPR) and the incidence of malaria [6-10]. In China, the annual malaria incidence is commonly used. Malaria incidence includes numbers of laboratory-confirmed malaria cases and other cases diagnosed with clinic symptoms (e.g. fever) as a numerator and the local population as a denominator. The local population size might be under- or overestimate because census is only carried out once 10 years in China. Huge population movement is common due to economic development in China in the last three decades. Thus, malaria incidence might be inaccurate due to limited health care resources [7] or under- or overestimates of population size [11]. It is important to estimate the burden of malaria accurately for planning public health interventions. Slide positivity rate (SPR) has been used as a surrogate to measure the incidence of malaria $[7,9,12,13]$, to define the level of malaria endemicity [11], and to identify malaria high risk areas [14]. This is a principal monitoring indicator in the malaria elimination programme in China for the period 2010 and 2020 and it has been monitored since the 1980s $[15,16]$ through the malaria annual 
reporting system. The changes in malaria incidence can be estimated from the SPR trends [7]. Some studies have demonstrated that SPR has steadily decreased with the decline in malaria incidence $[8,12]$, while others found that the annual parasite index (API) increased, but SPR kept steady at the same level over 20 years [8].

The development of the malaria early warning system (MEWS) has been started based on the surveillance system in China over recent years $[17,18]$. However, these studies are limited to climatic indicators and did not take advantage of monitoring indicators, which can help improve malaria prevention and control, especially in the early stage of malaria elimination. Moreover, the relationship between SPR and the incidence of malaria is not clear in the border areas of Yunnan Province, China. This study aimed to examine the role of SPR in monitoring malaria transmission, and improve the planning and implementation of malaria control and prevention programmes.

\section{Methods}

\section{Study site}

Mengla County is in south Yunnan Province and ranges from $21^{\circ} 09^{\prime}$ to $22^{\circ} 24^{\prime} \mathrm{N}, 101^{\circ} 05^{\prime}$ to $101^{\circ} 50^{\prime} \mathrm{E}$, bordering Myanmar to the west and Laos to the east, south and south-west as well as other counties of Yunnan Province to the north (Figure 1). It has an area of 7,093 sq km with an international border of $740.8 \mathrm{~km}$. Mengla County includes 10 townships and four farms with a population of 0.2 million. Its elevation ranges from $480 \mathrm{~m}$ to 2,023 $\mathrm{m}$. It is a high malaria transmission region. Malaria has been the top infectious disease for decades and was ranked the first (accounted for $46.7 \%$ of total cases) in all infectious diseases in 2003. Mengla was ranked top six for its annual malaria incidence $(400.4 / 100,000)$ among the 2,353 counties of China during 1994-1998 [19]. Malaria becomes one of the major public health problems in this region. Increased travel across international border (China-Myanmar and China-Laos) aggravates the burden of malaria $[2,20]$. In the national malaria elimination programme of China launched in 2010, Mengla was identified as one of the 75 first line counties in China and will achieve the goal of no indigenous malaria cases by 2017 and malaria elimination by 2020 [15].

\section{Data collection}

Data on annual malaria cases and SPR in all fever patients were obtained between 1993 and 2008 from the malaria annual reporting system in the Mengla Center for Disease Control and Prevention (CDC), China. Mengla is one of the sentinel counties selected for both national and provincial malaria surveillance, and has kept good records for malaria. The dominant species of parasitized by malaria is Plasmodium vivax, but Plasmodium falciparum infections also exist in this county. The ratio of $P$. vivax to P. falciparum cases was 4:1 [21]. Both species were combined in this study. SPR defined as the number of laboratory-confirmed positive slides examined per 100 slides, expressed as a percentage $[7,10]$. The calculation of SPR is

SPR for a year $=($ number of positive slides $/$ total slides examined $) \times 100$

Blood smears of febrile patients were examined, and confirmed by microscope and/or by rapid diagnostic test.

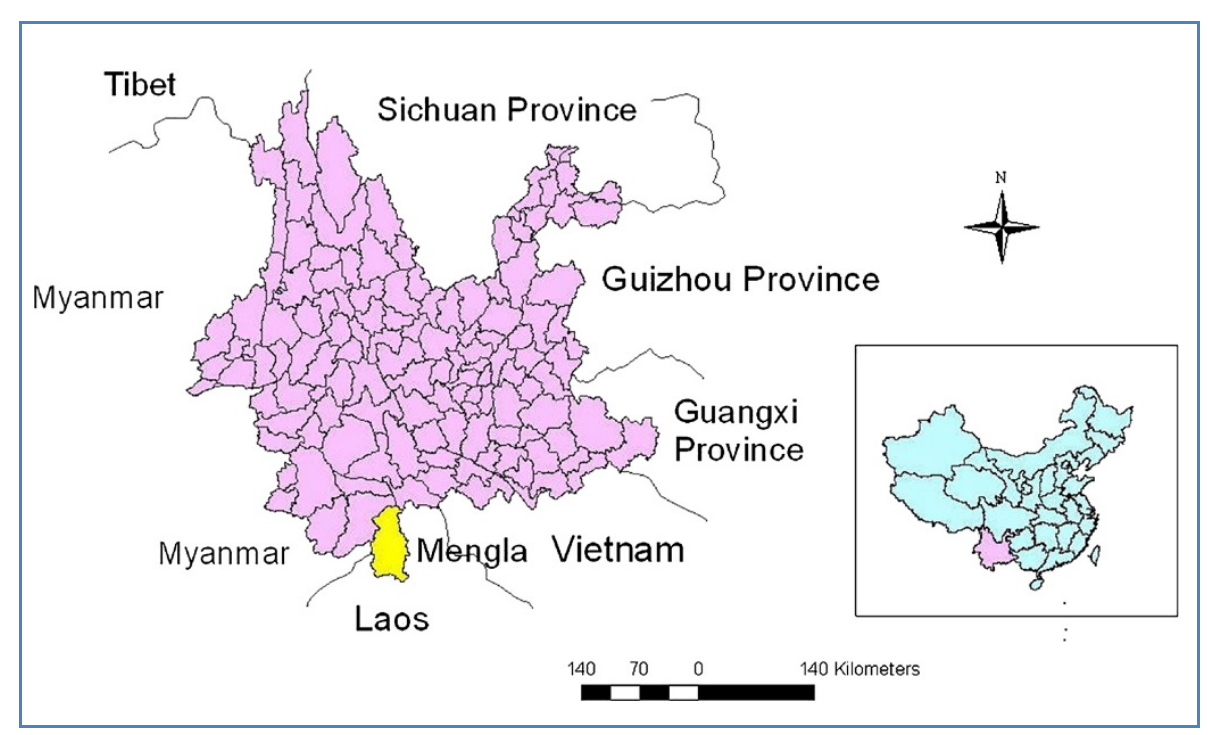

Figure 1 The location of Mengla County, Yunnan Province, China. 
Data on climatic variables (including annual average relative humidity, mean maximum temperature (Tmax), mean minimum temperature (Tmin) and rainfall); and the annual average income per capita of farmers and the population size of this county for the same period were retrieved from the Mengla Bureau of Meteorology and the Mengla Bureau of Statistics, respectively. An ethical approval was granted by the Human Research Ethics Committee, Queensland University of Technology (\#1000000573).

\section{Data analysis}

Spearman's correlation analyses were conducted to evaluate the correlations between SPR and the incidence of malaria, as well as other independent variables. Six stepwise multiple linear regression models were employed to examine the effects of SPR on malaria transmission after adjusting for confounding variables. Square root transformation was applied to the malaria incidence to assure the normality to satisfy the assumption of linear regression analysis. The Durbin-Watson (DW) statistic was used to detect the presence of autocorrelation (a relationship between values separated from each other) in the residuals (prediction errors) from the above regression analysis. If the DW statistic is substantially equal to two, it indicates no autocorrelation. Akaike Information Criterion (AIC) was used to select the most suitable model. All data analyses were conducted using SPSS for WinWrap Basic (PASW Statistics, Version 18).

\section{Results}

Figure 2 shows the annual pattern of malaria incidence and SPR in Mengla County. In this hyper-endemic region, a total of 8,962 malaria cases were reported and annual malaria incidence rates ranged from 23 to 648 per 100,000 , while the SPR varied between $0.42 \%$ and $13.08 \%$ from 1993 to 2008. The scatter plot with regression line depicts the crude relationships between incidence rates of malaria and SPR (Figure 3). The plot reveals that incidence rates of malaria were positively associated with SPR.

Spearman correlations between malaria incidence and socio-environment variables show (Table 1) that SPR $(\mathrm{r}=0.85, \mathrm{p}<0.01)$, income $(\mathrm{r}=-0.76, \mathrm{p}<0.01)$ and humidity $(\mathrm{r}=0.57, \mathrm{p}<0.05)$ were statistically significantly associated with malaria incidence. However, there was no significant association between other climatic variables and annual malaria incidence.

Six models have been used to evaluate the association between malaria incidence and predictors (Table 2). Model 1 shows SPR $(\beta=1.244, \mathrm{p}=0.000)$ alone can explain as high as $85 \%$ of the variation in the response variable. This provides strong evidence that SPR is a very good surrogate measure for the malaria incidence rates. Models 2-6 show that the inclusion of the additional covariates of Tmax, income and humidity moderately improved the model fit with the increase of adjusted $\mathrm{R}^{2}$ (88-95\%) and DW value (0.57-2.11), and decrease of AIC (75.93-65.62) in these models. Model $6\left(\mathrm{R}^{2}\right.$ : $95 \%$, AIC: 65.62$)$ is chosen as the optimal model due to its best goodness-of-fit of the data. In summary, the best fitting model includes SPR, income, maximum temperature and humidity as the predicting variables for the annual malaria incidence.

Table 3 displays crude and adjusted results from linear regression analyses. In crude models, four predictors were tested individually. Their adjusted $\mathrm{R}^{2}$ were $-3.2 \%$ (Tmax), 45\% (humidity), 47\% (income) and 85\% (SPR), respectively. In the multi-variable models, without SPR, only $54 \%$ of variation of malaria incidence was accounted for by the other three independent predictors (Tmax, humidity and income), whereas $95 \%$ of variation of the malaria incidence was explained after SPR was added to the model.

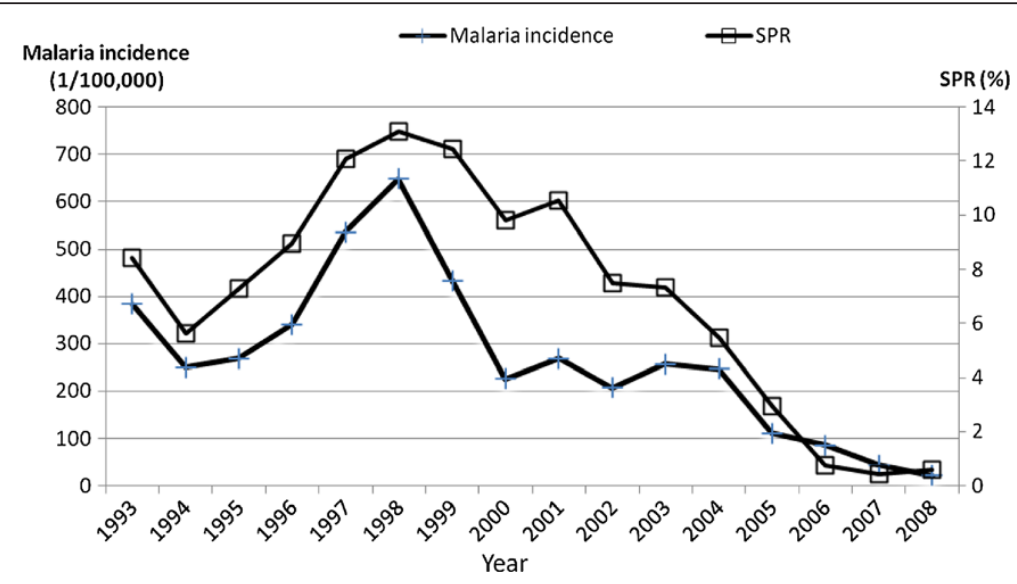

Figure 2 Malaria incidence and slide positivity rates (SPR) in Mengla County, China, 1993-2008. 


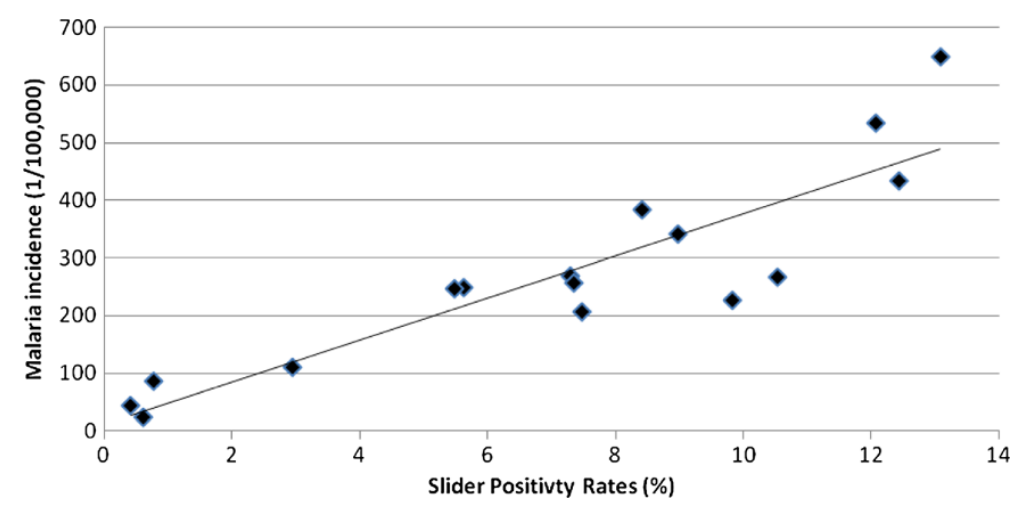

Figure 3 The relationship between slide positivity rates and crude malaria incidence in Mengla.

Table 3 also shows that SPR $(\beta=1.326, p<0.001)$ is a significantly independent predictor of malaria incidence after adjustment for Tmax, humidity and income. Keeping other independent variables constant, every $1 \%$ increase in SPR corresponds to an increase of $1.76 / 100,000$ (the squared malaria incidence) in malaria incidence rates.

Figure 4 shows the results of the regressive forecast chart in which Figure 4-A included SPR and Figure 4-B did not. Figure 4-A indicates that the predicted and the observed value of annual squared root malaria incidence rates matched well. The incidence rates in 1999, and in 2003 , were theoretically predicted by the model and validated by the observed values. However, for Figure 4-B the predicted and the observed value of the malaria incidence cannot be matched well, especially in year 199798. The observed values of these two years are out of the confidence interval. There is a wider confidence interval in Figure 4-B than in 4-A. All results stated that the regressive forecast of annual malaria incidence with SPR is more accurate than that without SPR in Mengla County over the study period.

\section{Discussion}

The results of this study indicate that SPR is a strong predictor of malaria incidence. SPR varied between $5.48 \%$ and $13.98 \%$ from 1993 to 2004 in Mengla. SPR under $2.9 \%$ is considered the absence of indigenous transmission [9]. Evidently, there is indigenous malaria transmission in Mengla [2,20]. Less than 5\% of SPR is considered the transition from the control stage to the pre-elimination stage [22] which implied that Mengla went through pre-elimination malaria after 2004. Five Anophiline species have been identified to be vectors of malaria in Yunnan Province [2,23]. Anopheles minimus is the major vector in this endemic border area - Mengla $[2,20]$.

SPR has been used as a surrogate of malaria incidence $[7,9,12]$. In Ugandan, SPR provided a useful measure to estimate malaria incidence among children [7]. To measure malaria transmission at a pre-elimination stage, SPR was used as an indicator to evaluate a malaria control programme on the island of Principe [12]. In current study, the decrease in SPR corresponded to the malaria incidence decline. This result is consistent with the result of other studies in which changes of SPR provided an alternative method for estimating changes in the incidence of malaria [7,12]. A downward trend in SPR in Mengla is in accordance with the decline of both P.vivax and P. falciparum malaria incidence in Yunnan [24]. After 2005, both SPR and malaria incidence sharply decreased in Mengla. This may be due to the impact of the Mekong Roll Back Malaria program (2002-2004) and the Global Fund (Round one) between 2003 and 2008, especially with the free treatment for malaria infection financed by the Global Fund in Mengla County since 2005.

Malaria transmission is greatly affected by socioeconomic conditions [25,26]. Low-middle income was significantly associated with malaria transmission in Indonesia [27]. The disappearance of malaria in some areas of Europe was associated with economic development [28]. In this study, income was negatively associated with malaria incidence. The decrease in malaria incidence was consistent with the increase in income.

Table 1 Spearman correlations between malaria incidence and social and climatic variables, 1993-2008

\begin{tabular}{lllllll}
\hline Variables & SPR & Income & Tmax & Tmin & Rainfall & Humidity \\
\hline Income & $-.544^{*}$ & & & & & \\
Tmax & -0.38 & 0.26 & & & & \\
Tmin & -0.04 & 0.39 & 0.27 & & & \\
Rainfall & 0.15 & -0.35 & -0.45 & -0.41 & & \\
Humidity & $.792^{* *}$ & $-.567^{*}$ & $-.515^{*}$ & -0.22 & 0.39 & \\
Malaria incidence & $.853^{* *}$ & $-.756^{* *}$ & -0.23 & -0.20 & 0.10 & $.568^{*}$ \\
${ }^{*} p<0.05$ & ${ }^{* *} p<0.01$ & & & & \\
\hline
\end{tabular}

SPR Slide positivity rates, Tmax Maximum temperature, Tmin Minimum temperature. 
Table 2 Association between malaria incidence and SPR in Mengla, China 1993-2008

\begin{tabular}{|c|c|c|c|c|c|c|}
\hline \multirow[t]{2}{*}{ Models } & \multicolumn{3}{|c|}{ SPR } & \multirow{2}{*}{$\begin{array}{l}\text { Adjusted } \\
\mathrm{R}^{2}\end{array}$} & \multirow[t]{2}{*}{ AIC } & \multirow{2}{*}{$\begin{array}{l}D-W \\
\text { (p-value) }\end{array}$} \\
\hline & $\beta$ & S.E. & $P$ & & & \\
\hline Model 1 & 1.244 & 0.133 & 0.000 & 0.851 & 75.93 & $0.78(=0.001)$ \\
\hline Model 2 & 1.359 & 0.128 & 0.000 & 0.884 & 74.36 & $0.57(<0.001)$ \\
\hline Model 3 & 1.039 & 0.137 & 0.000 & 0.895 & 72.79 & $1.12(=0.005)$ \\
\hline Model 4 & 1.152 & 0.110 & 0.000 & 0.939 & 67.32 & $1.21(=0.007)$ \\
\hline Model 5 & 1.318 & 0.163 & 0.000 & 0.924 & 70.67 & $1.54(=0.045)$ \\
\hline Model 6 & 1.326 & 0.131 & 0.000 & 0.951 & 65.62 & $2.11(=0.246)$ \\
\hline
\end{tabular}

SPR Slide positivity rates, $D-W$ Durbin-Watson, AIC Akaike Information Criterion, Model 1: SPR, Model 2: SPR+Tmax, Model 3: SPR +income, Model 4: SPR + Tmax + income, Model 5: SPR + Tmax + humidity, Model 6: $\mathrm{SPR}+$ Tmax + income + humidity;

This can be explained by the development of the general economy in Mengla County in the last two decades. Mengla is a poor region. Twenty-six ethnic minority groups accounted for $72 \%$ of the total population, and approximately $96 \%$ of Mengla is mountainous. The main income is from rice, rubber, cane sugar and tea (it is the place of origin of Pu Er tea) [29]. The local economy has been improved since the 1990s by planting rubber trees, tropical fruit trees, tea, and an increase in trade with Laos, Myanmar and other Mekong-river region countries. The incomes of farmers have gradually increased, which has led to better living conditions and improvements in sanitation and health. These improved socio-economic conditions may be one of the key reasons for the decreased malaria pattern in this region. Further investigation of the association between socioeconomic conditions and malaria transmission is warranted in this endemic area.

In this study, relative humidity has a significant positive association with malaria incidence. Relative humidity appears to have an effect on malaria transmission indirectly, as humidity may affect the development of the parasite, and the activity and survival of anopheline mosquitoes [27]. More humid and hotter than usual conditions may increase anopheline survival, thus resulting in an increase in outbreaks of malaria [30]. However, low humidity could reduce the numbers of the mature mosquitoes [31], therefore resulting in no malaria transmission
[27]. As a tropical rain forest area situated just south of the Tropic of Cancer, Mengla has wet and hot weather, which provides mosquitoes with favourable breeding sites.

Temperature has an important effect on the transmission cycle of the malaria parasite and mosquito survival $[25,32]$. Temperature is considered to play a crucial role in malaria transmission, which was identified by other studies [24,33-36] and is reported to be a predictor of malaria transmission. In a previous study in 2008, a positive association between minimum temperature, maximum temperature and malaria incidence based on monthly time series data was found in Mengla County [21]. However, the association between temperature and malaria incidence was not observed in current study. This may because annual weather variables are used for analysis. In multiple linear regression analysis, however, maximum temperature became a significant predictor of malaria transmission after adjustment for other factors. Maximum temperature and another three predictor factors together explained $95 \%$ of variance of malaria incidence.

Malaria transmission is influenced by various factors including climatic [37,38] and non-climatic factors [3941]. The spatial and seasonal distribution of malaria is largely determined by climate [42], and climatic factors (e.g. rainfall, temperature and humidity) have been widely used and recognized in the MEWS [43,44]. However, climatic factors are not enough for MEWS, which requires comprehensive and integrated indicators. To predict the timing and severity of malaria epidemics in MEWS, epidemiological surveillance indicators (for example SPR) should be considered $[45,46]$. Blood examination of parasite appearance is a key indicator in the early detection of malaria transmission and it is compulsorily reported in China. The use of SPR can obviously assist the development of MEWS in malaria elimination program in China. It can also be used to evaluate the malaria surveillance systems in China.

This study has several strengths. Firstly, this is the first study to examine the role of SPR in monitoring malaria transmission at a county level in China. Secondly, the model developed fitted the data quite well. The SPR alone, and combination with other predictors can explain $85 \%$ and

Table 3 Regression coefficients of the best model

\begin{tabular}{|c|c|c|c|c|c|c|c|c|c|c|}
\hline \multirow[b]{3}{*}{ Variables } & \multirow[b]{3}{*}{$\beta$} & \multirow{3}{*}{$\begin{array}{c}\text { Crude } \\
\text { S.E. }\end{array}$} & \multirow[b]{3}{*}{$P$} & \multirow[b]{3}{*}{ Adjusted $\mathrm{R}^{2}$} & \multicolumn{5}{|c|}{ Adjusted } & \\
\hline & & & & & \multicolumn{3}{|c|}{ Without SPR } & \multicolumn{3}{|c|}{ With SPR } \\
\hline & & & & & $\beta$ & S.E. & $P$ & $\beta$ & S.E. & $\mathbf{P}$ \\
\hline Tmax & -2.57 & 3.522 & 0.479 & -0.032 & 2.25 & 2.717 & 0.424 & 2.43 & 0.883 & 0.019 \\
\hline Humidity & 2.15 & 0.589 & 0.003 & 0.450 & 1.56 & 0.777 & 0.068 & -0.68 & 0.335 & 0.069 \\
\hline Income & -0.01 & 0.002 & 0.002 & 0.469 & 0.004 & 0.002 & 0.081 & -0.003 & 0.001 & 0.001 \\
\hline SPR & 1.24 & 0.133 & 0.000 & 0.851 & & & & 1.326 & 0.131 & 0.000 \\
\hline Adjusted $R^{2}$ & & & & & 0.536 & & & 0.951 & & \\
\hline
\end{tabular}

Multiple linear regression model: SPR + Tmax + humidity + income (model 6). 

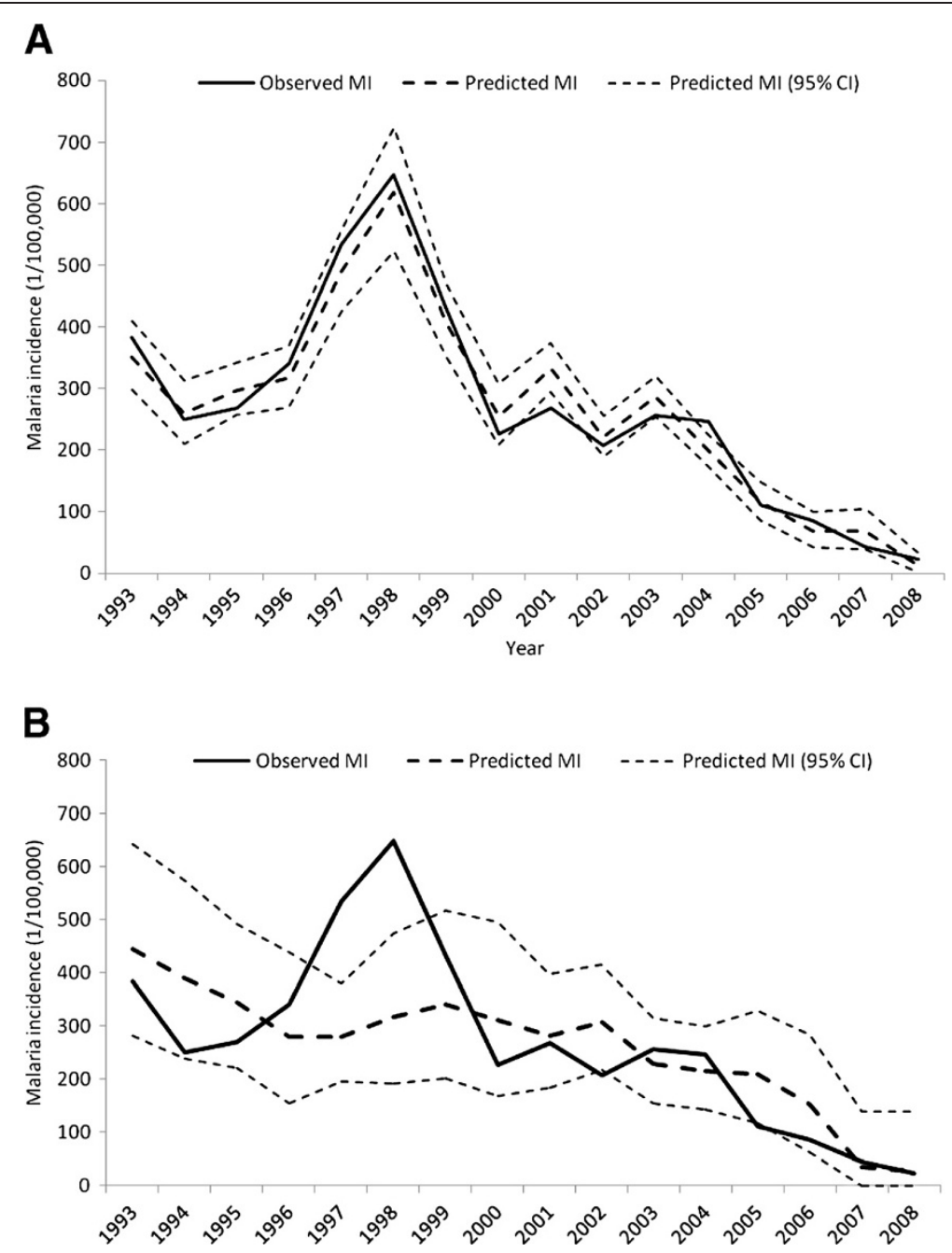

Figure 4 Regressive forecasts of annual malaria incidence in Mengla, China, 1993-2008, including SPR (A); and not including SPR (B).

95\% of variation in malaria transmission, respectively. Finally, the results of this study may help plan and implement malaria control and prevention interventions in the field.

The limitations of this study should also be acknowledged. Firstly, SPR and income were collected annually, and we were unable to examine the seasonal pattern of malaria transmission and conduct any finer analyses (e.g. monthly). Secondly, some other factors (e.g. mosquito density, movement of the people across the border and vegetation coverage) may play a role in the transmission of malaria. Because of the lack of the data, these factors were not adjusted for in the model. Finally, the data for this study were only collected from Mengla, Yunnan Province. There was no detailed information on $P$. vivax and $P$. falciparum, and the recurrence of $P$. vivax infection was also not considered, hence they could not be analysed separately. Thus, caution is needed when the findings of this study are generalized to other locations.
In conclusion, SPR was significantly associated with malaria incidence and identified as a strong predictor of malaria transmission in Mengla County. The results of this study support the use of SPR. The multi-variable regression model developed in this study may have implications for the global malaria elimination campaign. The improved understanding of the relationship between SPR and malaria transmission will assist in the establishment of a malaria early warning system to predict this wide spread disease in endemic areas.

\section{Competing interests}

The authors declare that they have no competing interests.

\section{Acknowledgements}

The authors thank Yunnan Center for Disease Control and Prevention for its support for field data collection in Yunnan Province, China. The authors thank Dr Gang Xie for the valuable advice on data analysis and model evaluation, Professor Pat Dale at Griffith University, School of Environment, for the comments on the earlier draft, and Ms Trish Gould at Queensland 
University of Technology, School of Public Health and Social Work, for the proof reading of the first manuscript

YB was funded by the Queensland University of Technology Postgraduate Research Award, Australia, and SLT was supported by a NHMRC Research Fellowship (\#553043).

\section{Author details}

'School of Public Health and Social Work, Institute of Health and Biomedical Innovation, Queensland University of Technology, Victoria Park Road, Kelvin Grove, 4059, Brisbane, Australia. ${ }^{2}$ Yunnan Center for Disease Control and Prevention, 158 Dongsi Road, 650022, Kunming, China. ${ }^{3}$ School of Population Health, University of Queensland, Herston Road, Herston, 4006, Brisbane, Australia. ${ }^{4}$ Mengla Center for Disease Control and Prevention, Mengla Nan Road, 666300, Xishuangbanna, China.

\section{Authors' contributions}

WBH and SLT initiated the study. YB, WBH and YMG designed the study and directed its implementation, including data analysis and interpreting. $\mathrm{HXL}$ YJX, SMC, LFZ and YB performed field data collection. SLT supervised the study and $Y B$ drafted the manuscript. All authors contributed to the manuscript edit, review and revising, and approved the final version of the manuscript.

\section{Received: 22 November 2011 Accepted: 18 April 2012}

Published: 18 April 2012

\section{References}

1. Zhou SS, Wang Y, Tang LH: Malaria Situation in the People's Republic of China in 2005. Chin J Parasitol Parasit Dis 2006, 24:401-403.

2. Zhu DF, Che LG, Su FC: The malaria situation on the frontiers of Yunnan Province, China. Southeast Asian J Trop Med Public Health 1994, 25:19-24.

3. Zhou SS, Wang Y, Fang W, Tang LH: Malaria Situation in the People's Republic of China in 2008. Chin J Parasitol Parasit Dis 2009, 27:455-457.

4. The malEra Consultative Group on Monitoring Evaluation Surveillance: A Research Agenda for Malaria Eradication: Monitoring, Evaluation, and Surveillance. PLoS Med 2011, 8:e1000400.

5. The malEra Consultative Group on Monitoring Evaluation Surveillance: A Research Agenda for Malaria Eradication: Health Systems and Operational Research. PLoS Med 2011, 8:e1000397.

6. Roberts DR, Laughlin LL, Hsheih P, Legters L: DDT, global strategies, and a malaria control crisis in South America. Emerg Infect Dis 1997. 3:295.

7. Jensen TP, Bukirwa H, Njama-Meya D, Francis D, Kamya MR, Rosenthal P, Dorsey G: Use of the slide positivity rate to estimate changes in malaria incidence in a cohort of Ugandan children. Malar J 2009, 8:213.

8. Metzger W, Giron A, Vivas-Martínez S, González J, Charrasco A, Mordmüller B, Magris M: A rapid malaria appraisal in the Venezuelan Amazon. Malar J 2009, 8:291

9. Subbarao SK, Vasantha K, Raghavendra K, Sharma V, Sharma G: Anopheles culicifacies: siblings species composition and its relationship to malaria incidence. J Am Mosa Control Assoc 1988, 4:29.

10. Montanari R, Bangali A, Talukder K, Baqui A, Maheswary N, Gosh A, Rahman M, Mahmood A: Three case definitions of malaria and their effect on diagnosis, treatment and surveillance in Cox's Bazar district, Bangladesh. Bull World Health Organ 2001, 79:648-656.

11. Hay SI, Guerra CA, Tatem AJ, Noor AM, Snow RW: The global distribution and population at risk of malaria: past, present, and future. Lancet Infect Dis 2004, 4:327-336.

12. Lee PW, Liu CT, Rampao H, do Rosario V, Shaio MF: Pre-elimination of malaria on the island of Príncipe. Malar J 2010, 9:26.

13. Roy SB, Sarkar RR, Sinha S: Theoretical investigation of malaria prevalence in two Indian cities using the response surface method. Malar J 2011, 10:301.

14. Joshi PL, Chandra R, Bhattacharya M, Vaish HC: Validity of using slide positivity rate (SPR) in identification of high risk malarious segments in rural areas. J Commun Dis 1997, 29:41.

15. China Malaria Elimination Plan [http://www.moh.gov.cn/publicfiles/business/ htmlfiles/mohjbyfkzj/s3593/201005/47529.htm]

16. China National Malaria Office of Global Fund: Management and technique program in high malaria transmission areas in China. Shanghai; 2003.

17. Wen L, Yang ZF, Xu DZ, Zhang ZY: Malaria surveillance and warning system based on GIS in Hainan Provine, China. J Prev Med Chin People's Liberation Army 2006, 24:458-460.
18. Yang GJ, Zhou XN, Malone JB, McCarroll JC, Wang TP, Liu JX: Application of multifactor spatial composite model to predict transmission tendency of malaria at national level. Chin J Parasitol Parasit Dis 2002, 20:145-147.

19. Gao CY, Chai GJ, Han GH, Yang XW, Liu L, Jiang ZJ: Time trend analysis of malaria incidence in China: 1950-2001. Chin J of Public Health 2003 19:725-726.

20. Hu H, Singhasivanon P, Salazar NP, Thimasarn K, Li XZ, Wu YX, Yang H, Zhu DF, Supavej S, Looarecsuwan S: Factors influencing malaria endemicity in Yunnan Province, PR China (analysis of spatial pattern by GIS). Geographical Information System. Southeast Asian J Trop Med Public Health 1998, 29:191-200.

21. Tian LW, Bi Y, Ho SC, Liu WJ, Liang S, Goggins WB, Chan EY, Zhou SS, Sung $\mathrm{JJ}$ : One-year delayed effect of fog on malaria transmission: a time-series analysis in the rain forest area of Mengla County, south-west China. Malar J 2008, 7:110.

22. Aregawi M, Cibulskis R, Otten M, Williams R, Dye C: World Malaria Report, 2008. Geneva, Switzerland: World Health Organization; 2008.

23. Bureau of Endemic Diseases Control of People's Republic of China1998Manual of Malaria ControlPeople's Health Publishing CompanyBeijingBureau of Endemic Diseases Control of People's Republic of China: Manual of Malaria Control. Beijing: People's Health Publishing Company; 1998.

24. Clements A, Barnett AG, Cheng ZW, Snow RW, Zhou HN: Space-time variation of malaria incidence in Yunnan province, China. Malar J 2009, 8:180.

25. Brooker S, Clarke S, Njagi JK, Polack S, Mugo B, Estambale B, Muchiri E, Magnussen P, Cox J: Spatial clustering of malaria and associated risk factors during an epidemic in a highland area of western Kenya. Trop Med Int Health 2004, 9:757-766.

26. McMichael AJ, Woodruff RE, Hales S: Climate change and human health: present and future risks. Lancet 2006, 367:859-869.

27. Dale P, Sipe N, Anto S, Hutajulu B, Ndoen E, Papayungan M, Saikhu A, Prabowa Y: Malaria in Indonesia: a summary of recent research into its environmental relationships. Southeast Asian J Trop Med Public Health 2005, 36:1-13.

28. ljumba JN, Lindsay SW: Impact of irrigation on malaria in Africa: paddies paradox. Med Vet Entomol 2001, 15:1-11.

29. Mengla County introduction [http://baike.baidu.com/view/769085.htm]

30. Zucker JR: Changing patterns of autochthonous malaria transmission in the United States: a review of recent outbreaks. Emerg Infect Dis 1996, 2:37.

31. Keiser J, Utzinger J, Singer BH: The potential of intermittent irrigation for increasing rice yields, lowering water consumption, reducing methane emissions, and controlling malaria in African rice fields. J Am Mosq Control Assoc 2002, 18:329.

32. Martens W, Niessen LW, Rotmans J, Jetten TH, McMichael AJ: Potential impact of global climate change on malaria risk. Environ Health Perspect 1995, 103:458

33. Bi P, Tong SL, Donald K, Parton KA, Ni J: Climatic variables and transmission of malaria: a 12-year data analysis in Shuchen County, China. Public Health Rep 2003, 118:65

34. Kleinschmidt I, Sharp B, Clarke G, Curtis B, Fraser C: Use of generalized linear mixed models in the spatial analysis of small-area malaria incidence rates in KwaZulu Natal, South Africa. Am J Epidemiol 2001, 153:1213.

35. Lindsay S, Birley M: Climate change and malaria transmission. Ann Trop Med Parasitol 1996, 90:573-588.

36. Zhou GF, Minakawa N, Githeko AK, Yan GY: Climate variability and malaria epidemics in the highlands of East Africa. Trends Parasitol 2005, 21:54-56.

37. Berrang-Ford L, MacLean JD, Gyorkos TW, Ford JD, Ogden NH: Climate change and malaria in Canada: a systems approach. Interdiscip Perspect Infect Dis 2009, doi:10.1155/2009/385487.

38. Roll Back Malaria Cabinet Project2001Malaria early warning system: concepts, indicators and partners (A framework for field research in Africa) World Health OrganizationGeneva, SwitzerlandRoll Back Malaria Cabinet Project: Malaria early warning system: concepts, indicators and partners (A framework for field research in Africa). Geneva, Switzerland: World Health Organization; 2001.

39. Githeko AK, Lindsay SW, Confalonieri UE, Patz JA: Climate change and vectorborne diseases: a regional analysis. Bull World Health Organ 2000, 78:1136-1147.

40. Lindsay S, Martens W: Malaria in the African highlands: past, present and future. Bull World Health Organ 1998, 76:33.

41. Reiter P: Climate change and mosquito-borne disease. Environ Health Perspect 2001, 109:141.

42. Tanser FC, Sharp B, le Sueur D: Potential effect of climate change on malaria transmission in Africa. Lancet 2003, 362:1792-1798. 
43. Hay SI, Were EC, Renshaw M, Noor AM, Ochola SA, Olusanmi I, Alipui N, Snow RW: Forecasting, warning, and detection of malaria epidemics: a case study. Lancet 2003, 361:1705-1706.

44. Thomson MC, Doblas-Reyes FJ, Mason SJ, Hagedorn R, Connor SJ, Phindela T, Morse AP, Palmer TN: Malaria early warnings based on seasonal climate forecasts from multi-model ensembles. Nature 2006, 439:576-579.

45. Thomson MC, Connor SJ: The development of malaria early warning systems for Africa. Trends Parasitol 2001, 17:438-445.

46. Ceccato P, Connor S, Jeanne I, Thomson M: Application of Geographical Information Systems and Remote Sensing technologies for assessing and monitoring malaria risk. Parassitologia 2005, 47:81-96.

doi:10.1186/1475-2875-11-117

Cite this article as: Bi et al: Can slide positivity rates predict malaria transmission?. Malaria Journal 2012 11:117.

\section{Submit your next manuscript to BioMed Central} and take full advantage of:

- Convenient online submission

- Thorough peer review

- No space constraints or color figure charges

- Immediate publication on acceptance

- Inclusion in PubMed, CAS, Scopus and Google Scholar

- Research which is freely available for redistribution 